\title{
Corrigendum: Relationships between chemical structures and functions of triterpene glycosides isolated from sea cucumbers
}

\author{
Jong-Young Kwak* \\ Department of Biochemistry, School of Medicine, Dong-A University, Busan, South Korea \\ *Correspondence: jykwak@dau.ac.kr \\ Edited and reviewed by: \\ Antonio Trincone, Istituto di Chimica Biomolecolare, Consiglio Nazionale delle Ricerche, Italy
}

Keywords: anticancer activity, cucumarioside, frondoside A, membrane transporters, stichoposides, triterpene glycosides

\section{A corrigendum on}

Relationships between chemical structures and functions of triterpene glycosides isolated from sea cucumbers by Park, J,-I., Bae, H,-R., Kim, C. G., Stonik, V. A., and Kwak, J.-Y. (2014). Front. Chem. 2:77. doi: 10.3389/fchem.2014. 00077

The authors corrected structures of compounds in Figures 2, 4, 6, and 9.
1. The structures of compounds $(3,4,5$, $6,10,15,20$, and 21) are corrected.

2. Compounds 17 and 18 (in Figure 7) are same as compounds 20 and 21 (in Figure 9).

Conflict of Interest Statement: The author declares that the research was conducted in the absence of any commercial or financial relationships that could be construed as a potential conflict of interest.

Received: 13 October 2014; accepted: 30 October 2014; published online: 13 November 2014.
Citation: Kwak J-Y (2014) Corrigendum: Relationships between chemical structures and functions of triterpene glycosides isolated from sea cucumbers. Front. Chem. 2:103. doi: $10.3389 /$ fchem.2014.00103

This article was submitted to Chemical Biology, a section of the journal Frontiers in Chemistry.

Copyright () 2014 Kwak. This is an open-access article distributed under the terms of the Creative Commons Attribution License (CC BY). The use, distribution or reproduction in other forums is permitted, provided the original author(s) or licensor are credited and that the original publication in this journal is cited, in accordance with accepted academic practice. No use, distribution or reproduction is permitted which does not comply with these terms. 


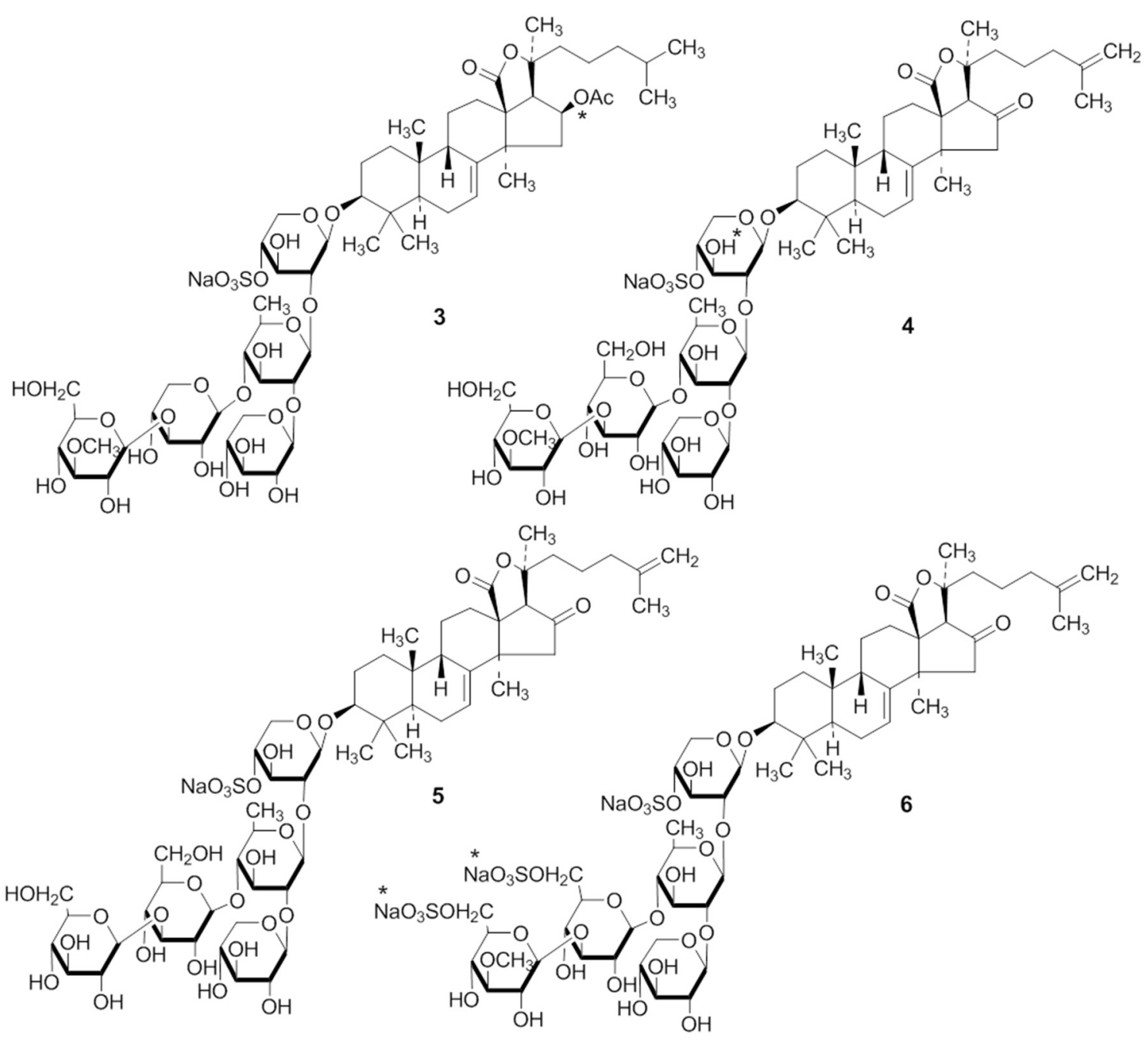

FIGURE 2 | The structures of 3, 4, 5 and 6 are corrected. 

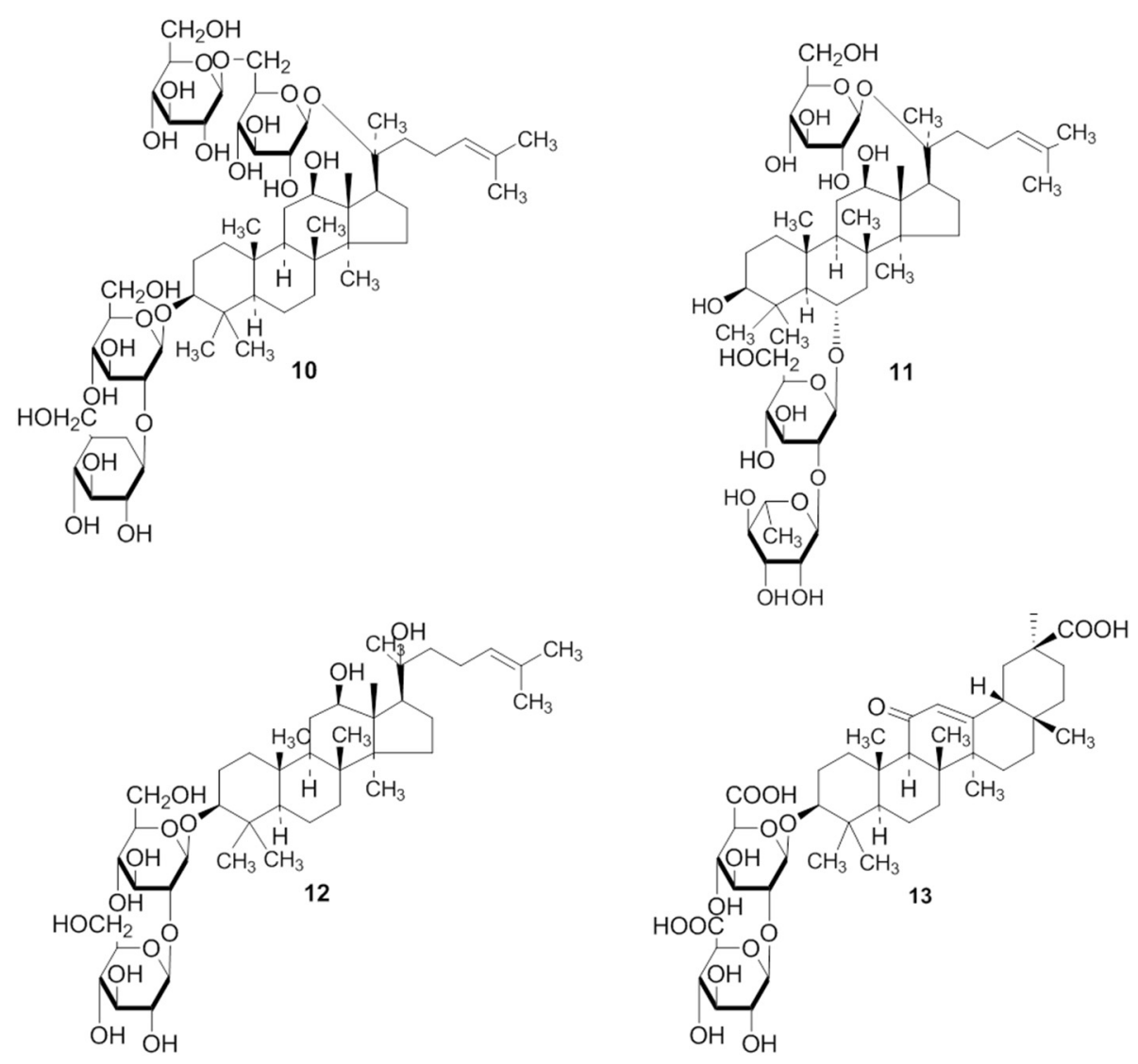

FIGURE 4 | The structure of 10 is corrected.

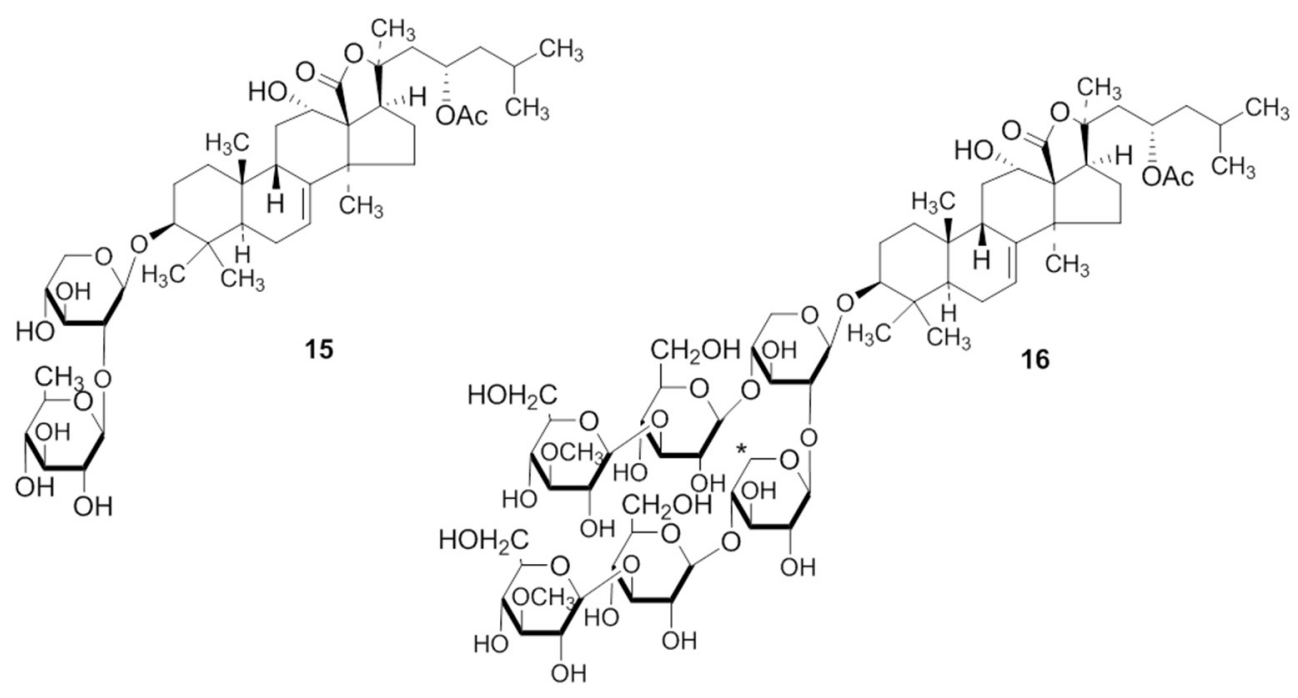

FIGURE 6 | The structure of 15 is corrected. 


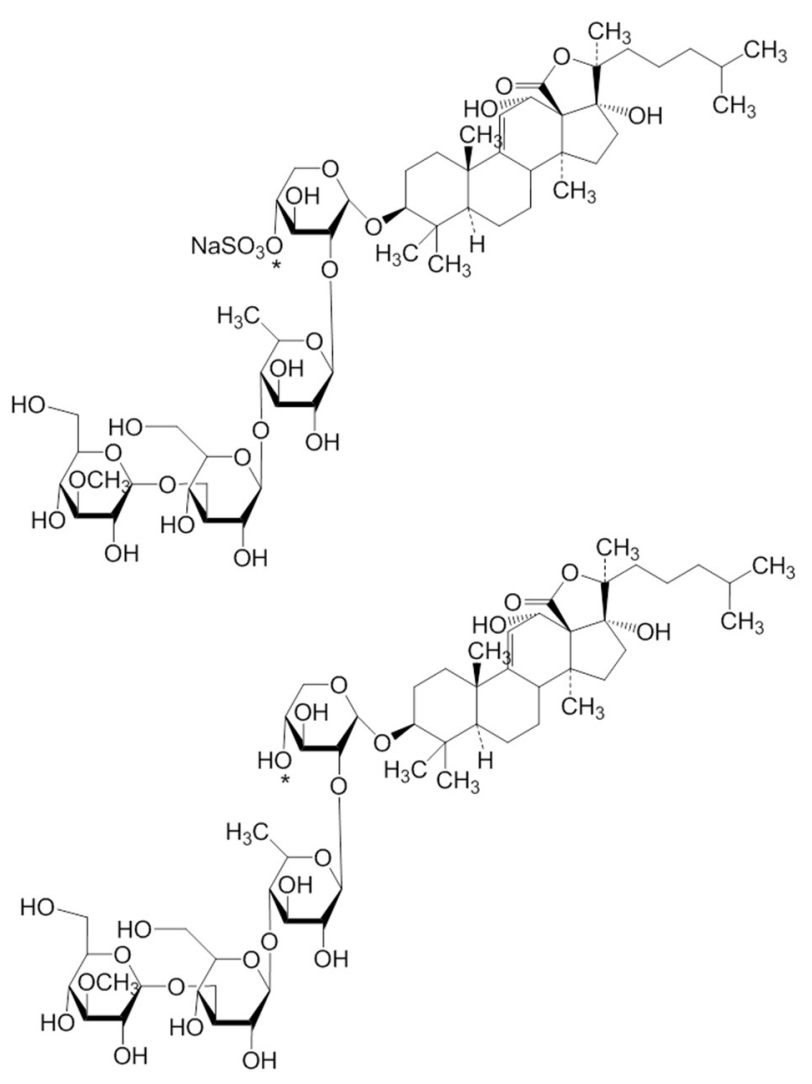

FIGURE 9 | The structures of 20 and 21 are corrected. 